\title{
Analysis of the structure of door bottom drop sealing device
}

\author{
Yuan Fei \\ HÄFELE Hardware Technology (China) Co., Ltd. No. Jia 25, Yuhua Road, Area B Tianzhu Airport Industrial Zone Shunyi District \\ Beijing 101318, China
}

\begin{abstract}
Drop Seals Is A Kind Of Hardware That Can Solve The Tightness Of The Door Bottom. This article will briefly introduce the common structural features of this hardware and analyze its impact on the sound insulation of the door leaf according to the experiment. Based on the comparative analysis of 5 sets of data, the experiment proved the effectiveness of the drop seals for the door bottom seal.
\end{abstract}

\section{Introduction}

With the continuous improvement of construction technology, the performance of building components has been greatly improved. As a very traditional building component, the door has always been used to divide space. As people's demands for home improvement become more diversified, the sound insulation effect of interior doors is gradually being valued. After continuous upgrading of filling materials and optimization of door mechanisms, the sound insulation effect of doors has been greatly improved. But the sound can be transmitted through the gap between the door leaf and the door frame, especially the sound transmission at the bottom has become the technical bottleneck of door sound insulation.

The door bottom can be sealed by the door threshold and the sealing strip, same with the door frame. However, the shortcomings are obvious. The door threshold will greatly affect indoor traffic, especially for children, the elderly, the disabled and other people with limited mobility.

Another solution is to install a door bottom drop sealing device (hereinafter referred to as drop seals) on the bottom of door leaf. This scheme completely avoids the restrictions on passability by the threshold. Drop seals have been widely used in Europe, and more and more domestic consumer groups have accepted this design. This article will analyze the working principle and effect of this device.

\section{Structure principle}

The drop seals is composed of a shell, a lever structure, a start key and a drop mechanism The shell is mostly aluminum profiles, made by squeeze forming. The start key is connected with the linkage mechanism. The start key used to be the side of the door hinge, and the longer product will have a start button at both ends of the door leaf, as shown in 2.2. When the door is closed, the start key contacts the door frame, triggers the lever structure, and pushes out the drop mechanism to realize the door bottom seal. Especially, when the door bottom seal is working, the drop mechanism will not extend horizontally. When one side of drop mechanism touches the floor, the lever structure will automatically correct the posture of the drop mechanism, Even if there is a slight non-parallelism between the floor and the bottom of door leaf. It can also make the drop mechanism fit the floor completely, so the design of the freedom degree of the lever structure is important for this hardware, as shown in 2.3. There are many kinds of lever structure for drop seals. The lever structure will affect the service life of the drop seals, applicability of different door widths and the using effect. Brief introduction as follows.

2.1 The single lever structure is simple and reliable. But in order to avoid the lever structure is too long, it cannot suitable for too wide door leaf.

Fei.yuan@hafele.com.cn 

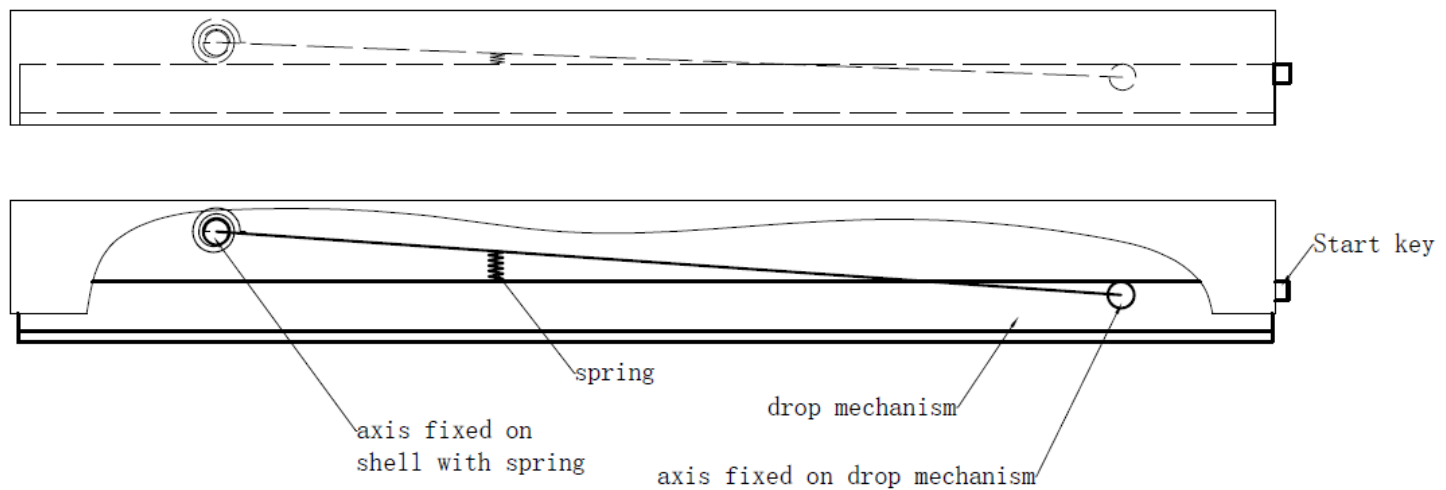

Fig 1. The single lever structure

\subsection{The drop mechanism is driven by the deformation force of the metallic reed or steel wire.}

applied to heavier door leaves. The figure below shows the

Generally, the restoring force is relatively large and can be
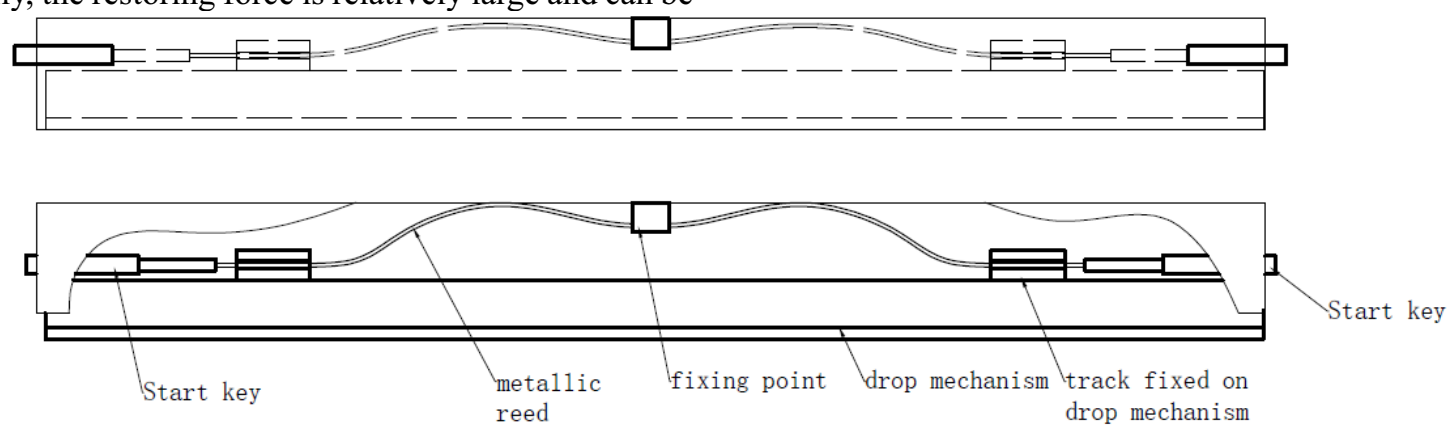

Fig 2. The double start key

\section{3 multi-lever structure. The mechanism is}

more flexible and can be easily driven. The following figure shows the state of asymmetrical extension of the drop mechanism.
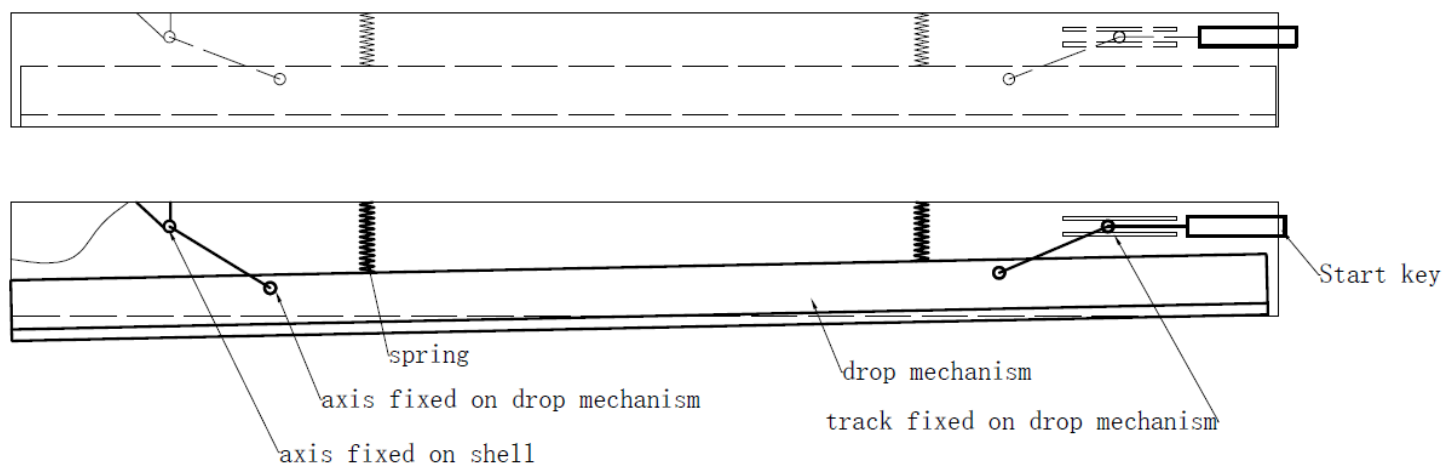

Fig 3. The multi-lever structure

In addition to the lever mechanism, the structure and size of the drop mechanism will have a greater impact on product performance, especially the sound insulation. In actual using. It seals the door bottom gap through the drop mechanism to reduce the transmission of sound through the gap, thereby improving the sound insulation of the door leaf. This article will test and analyze the two different width products shown in Figure 4 and Figure 5.

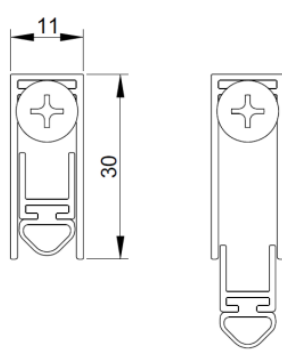

Fig 4. the width products A 


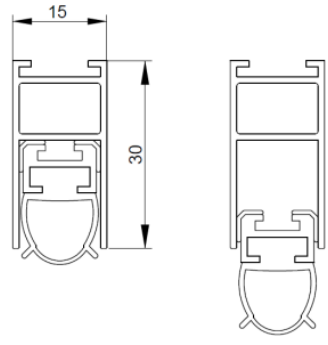

Fig 5. the width products B

\section{Sound insulation experiment}

\subsection{Experiment Overview}

This experiment will measure the sealing effect of different drop seals on the door bottom gap, and analyze the influence on the sound insulation of the door leaf. The experiment set 5 groups.

Group A. The gaps between the door leaf and the door frame and the ground are all sealed with sealant. The door bottom gap is $4 \mathrm{~mm}$. This group as the standard value of the sound insulation of the test piece without sound spreading through the gap.

Group B. The drop seals shown in Figure 4 is installed at the bottom of the door leaf. The door bottom gap is $4 \mathrm{~mm}$. The door leaf and the door frame are sealed. Simulate the sound insulation effect of in actual using.

Group C. The drop seals shown in Figure 5 is installed at the bottom of the door leaf. The door bottom gap is $4 \mathrm{~mm}$. The door leaf and the door frame are sealed. Simulate the sound insulation effect of in actual using.

Group D. The drop seals shown in Figure 4 is installed at the bottom of the door leaf. The door bottom gap is $10 \mathrm{~mm}$. The door leaf and the door frame are sealed. Simulate the sound insulation effect when sealing large gaps with drop seals.

Group E. The drop seals shown in Figure 5 is installed at the bottom of the door leaf. The door bottom gap is $10 \mathrm{~mm}$. The door leaf and the door frame are sealed.
Simulate the sound insulation effect when sealing large gaps with drop seals.

According to the requirements of BS EN ISO 101402 , the test room is a standard reverberation room that width of 5.49 meters and height of 2.58 meters from the floor to the ceiling. It consists of a sound source room and a receiving room, with a test hole in between. The volume of the sound source room is $86 \mathrm{~m}^{3}$, and the volume of the receiving room is $67.8 \mathrm{~m}^{3}$. The gap between the test hole and the test door is blocked by a caulking wall. The caulking wall is dense, and according to the Quality Law, the transmission of sound through the caulking wall is negligible. The test door is a wooden flush door, the door leaf size is $926 \mathrm{~mm}$ width, $2040 \mathrm{~m}$ height, $54 \mathrm{~mm}$ thickness. At the bottom of the door, there is a slot for install the drop seals. The caulking wall at the bottom of the door leaf is equipped with removable acrylic plate to meet the experimental requirements of different door bottom gaps [1]. The test equipment is arranged according with ISO 10140-2:2010 requirements.

In the experiment, the sound intensity LP1 of the sound source room and the sound intensity LP2 of the receiving room were tested each third octave frequency between $100 \mathrm{~Hz}$ to $5000 \mathrm{~Hz}$. Calculate the sound reduction index R of the test door by the test results of the frequency range from $100 \mathrm{~Hz}$ to $3150 \mathrm{~Hz}$ refer the following formula. Where $\mathrm{S}$ is the area of the test door, $\mathrm{T}$ is the reverberation time of the receiving chamber, and $\mathrm{V}$ is the volume of the receiving room. Calculate the weighted sound reduction index Rw according to the requirements of ISO 717$1: 2013$

$$
\mathrm{R}=\mathrm{L}_{\mathrm{P} 1}-\mathrm{L}_{\mathrm{P} 2}+10 \lg (\mathrm{ST} / 0.16 \mathrm{~V})
$$

\section{Test results and analysis}

4.1 In group $\mathrm{A}$, sound weighted reduction index $\mathrm{R}_{\mathrm{W}}=39 \mathrm{~dB}$. The specimen with seamless transmission has the highest sound insulation, and the sound can only be transmitted through the door leaf, door frame and sealant.

Table1. group A

\begin{tabular}{|c|c|c|c|c|c|c|c|c|c|c|c|c|c|c|c|c|}
\hline$(\mathrm{Hz})$ & 100 & 125 & 160 & 200 & 250 & 315 & 400 & 500 & 630 & 800 & 1000 & 1250 & 1600 & 2000 & 2500 & 3150 \\
\hline $\mathrm{R}(\mathrm{dB})$ & 21.1 & 28.2 & 27.2 & 25.2 & 30.8 & 31.5 & 33.7 & 35.6 & 37.7 & 40.3 & 42.4 & 42.1 & 43.4 & 42 & 40.4 & 42 \\
\hline
\end{tabular}




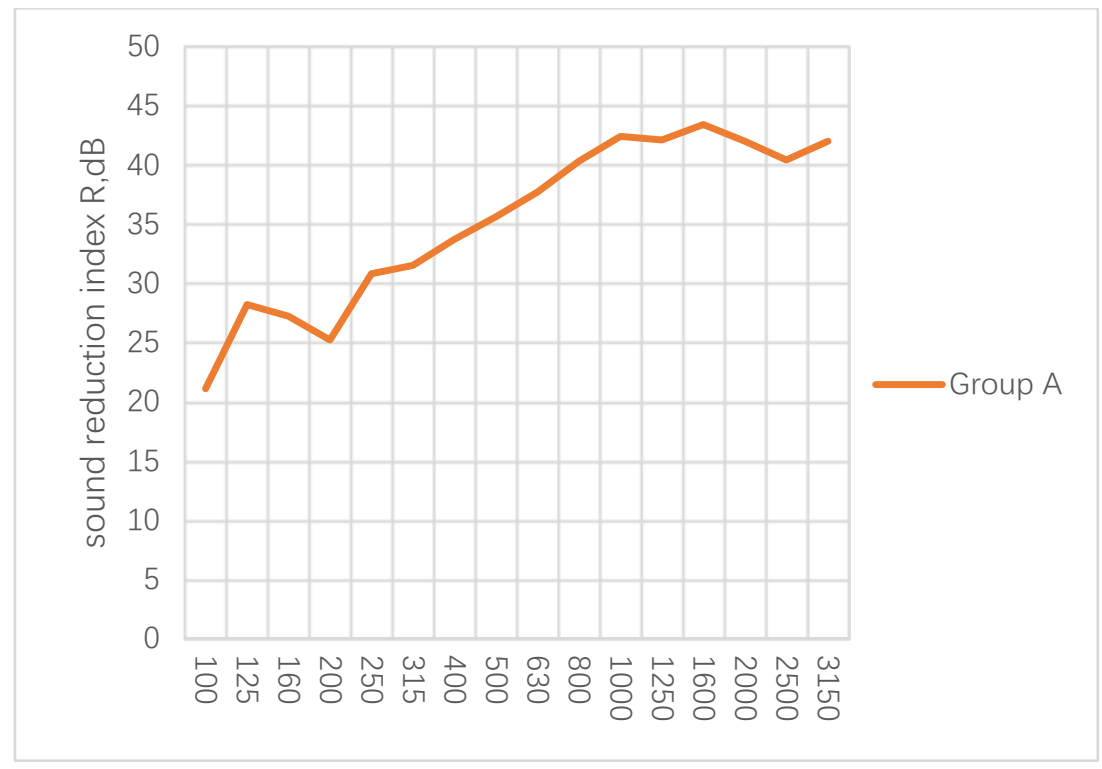

Fig 6. Sound reduction index of group A

4.2 Group B and C simulate the door in actual using. Group B weighted sound insulation $\mathrm{R}_{\mathrm{W}}=37 \mathrm{~dB}$, Group $\mathrm{C}$ weighted sound insulation $\mathrm{R}_{\mathrm{W}}=38 \mathrm{~dB}$. Compared with the group A, the overall sound insulation is not significantly reduced. In particular, the sound insulation of group $C$ has almost no change. Obviously, through the structures of FIGS. 4 and 5 that the sound insulation of FIG. 5 with a wider drop mechanism is slightly greater than that of FIG. 4.

Table2. group B

\begin{tabular}{|l|c|c|c|c|c|c|c|c|c|c|c|c|c|c|c|c|}
\hline$(\mathrm{Hz})$ & 100 & 125 & 160 & 200 & 250 & 315 & 400 & 500 & 630 & 800 & 1000 & 1250 & 1600 & 2000 & 2500 & 3150 \\
\hline $\mathrm{R}(\mathrm{dB})$ & 21.1 & 31.6 & 30.7 & 27.8 & 33.8 & 33.2 & 33.3 & 33.4 & 34.3 & 35.6 & 37.4 & 38.4 & 39.2 & 37.8 & 37.5 & 36.1 \\
\hline
\end{tabular}

Table3. group C

\begin{tabular}{|l|l|l|l|l|l|l|l|l|l|l|l|l|l|l|l|l|}
\hline$(\mathrm{Hz})$ & 100 & 125 & 160 & 200 & 250 & 315 & 400 & 500 & 630 & 800 & 1000 & 1250 & 1600 & 2000 & 2500 & 3150 \\
\hline $\mathrm{R}(\mathrm{dB})$ & 15.9 & 31.5 & 30.2 & 28.1 & 35.9 & 34.3 & 34.4 & 34.8 & 36.6 & 38.6 & 39 & 40.7 & 41.4 & 41.1 & 39.6 & 40.2 \\
\hline
\end{tabular}

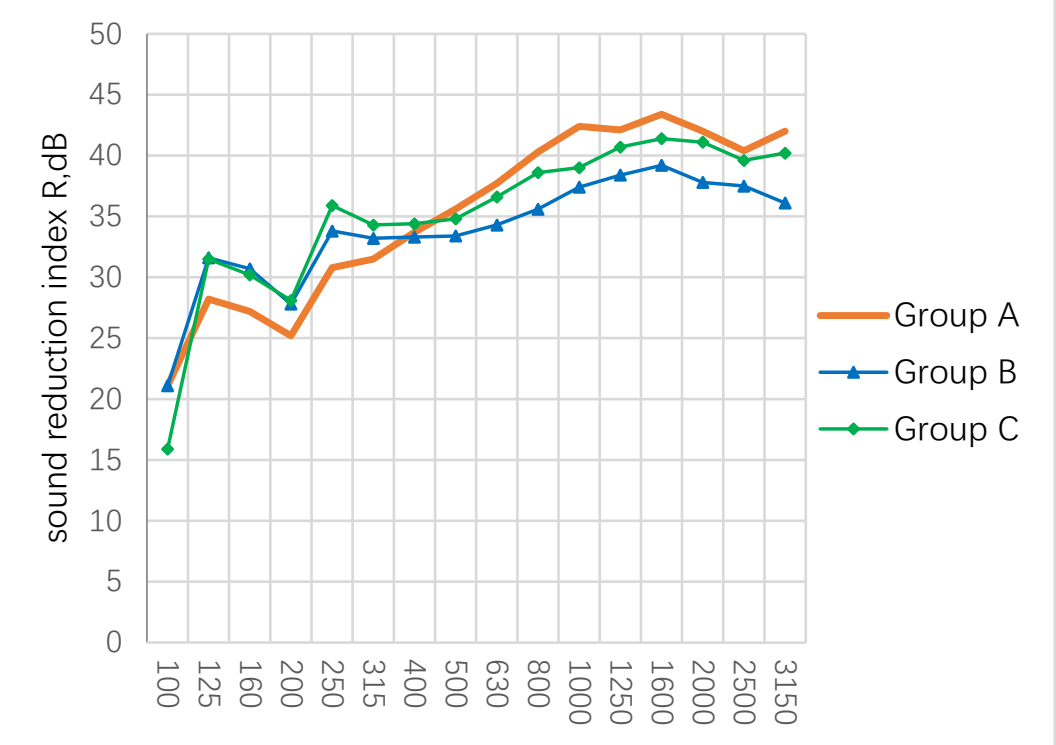

Fig 7. Comparison of sound reduction index between group A B and C 
4.3 Set the bottom of the door leaf of group D and E to have a $10 \mathrm{~mm}$ gap by adjusting the door bottom acrylic plate. In this situation, the drop mechanism should extend fully, but it is still within the working range. The weighted sound reduction index is $\mathrm{R}_{\mathrm{W}}=33 \mathrm{~dB}$ for group $\mathrm{D}$ and $\mathrm{R}_{\mathrm{W}}=37$ for group $\mathrm{E}$. The sound insulation of the two products is lower than group B and group C what with normal gap between with door leaf and caulking wall. The sound insulation of the product in Figure 4 has dropped significantly. However, the sound insulation of the product in Figure 5 has a less obvious drop. It also proves the conclusion of 4.2 that the wider drop mechanism has better sound insulation.

Table4. Group D

\begin{tabular}{|c|c|c|c|c|c|c|c|c|c|c|c|c|c|c|c|c|}
\hline$(\mathrm{Hz})$ & 100 & 125 & 160 & 200 & 250 & 315 & 400 & 500 & 630 & 800 & 1000 & 1250 & 1600 & 2000 & 2500 & 3150 \\
\hline $\mathrm{R}(\mathrm{dB})$ & 25.5 & 32.8 & 31 & 24.8 & 32 & 31.3 & 32.4 & 31.6 & 32.1 & 31.2 & 30.9 & 32.8 & 34 & 35.6 & 35.5 & 36.4 \\
\hline
\end{tabular}

Table5. Group E

\begin{tabular}{|c|c|c|c|c|c|c|c|c|c|c|c|c|c|c|c|c|}
\hline$(\mathrm{Hz})$ & 100 & 125 & 160 & 200 & 250 & 315 & 400 & 500 & 630 & 800 & 1000 & 1250 & 1600 & 2000 & 2500 & 3150 \\
\hline $\mathrm{R}(\mathrm{dB})$ & 20.4 & 30.7 & 29.8 & 27.4 & 33.1 & 33.4 & 34 & 33 & 36 & 37.2 & 37.8 & 38.5 & 38.6 & 37.7 & 36.7 & 39.7 \\
\hline
\end{tabular}

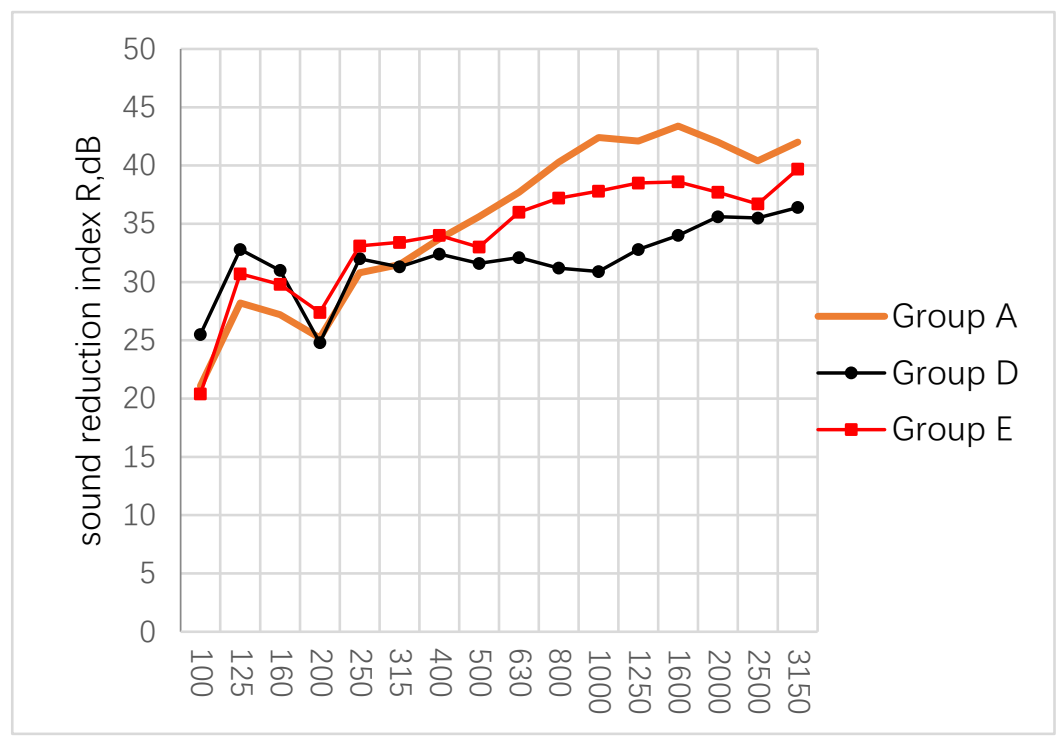

Fig 8. Comparison of sound reduction index between group A D and E

4.4 Especially. In the frequency below $400 \mathrm{~Hz}$, the sound insulation of BCDE group is greater than or close to group A. It shows that the sound insulation effect of the drop seals in this frequency is better than that of the sealant in this experimental condition. This may be due to the influence of the reflection of sound waves between the multilayer materials in the drop mechanism.

\section{Conclusion}

5.1 This experiment show that in order to enhance the sound insulation effect of the door, the sound insulation effect of the indoor room can be effectively achieved by setting the drop seals without setting the threshold. This design has broad application prospects especially in hospitals, schools, hotels and other public places with high sound insulation requirements.
5.2 Sound transmission through the door gap is obvious. When the door bottom gap reaches $10 \mathrm{~mm}$, the sound insulation capacity will significantly decrease under the same conditions. Therefore, the size of the slit crosssection is an important factor in the transmission of the indoor sound field, especially the change of the door bottom gap has a greater impact on the sound insulation effect. Therefore, in product design, the size of the gap at the bottom of the door should be minimized. In addition, during the installation process of building components, the installation accuracy should be strictly controlled to ensure the sound insulation of the entire door system.

5.3 This experiment show that the width of the drop seals will affect the sound insulation of the door leaf. When the gap at the bottom of the door is increased from $4 \mathrm{~mm}$ to $10 \mathrm{~mm}$, the sound insulation effect of using the same sound insulation strip is reduced. If you want to maintain the same sound insulation effect, increasing the width of the 
drop seals will have a significant sound insulation effect. The greater the width of the drop seals, the greater the volume of sound insulation, and the better the sound insulation effect.

\section{References}

1. CUI Cheng-xun. Analysis on Sound Reduction Index of Interior Door with Aperture at Bottom

2. CHEN Xingwang, LI Zhengguang, DI Guoqing. A SEAL DEVICE BETWEEN CIVIL DOOR BOTTOM AND FLOOR

3. DIN EN ISO 717-1-2013

4. DIN EN ISO 10140-2-2010 